\title{
A experiência do usuário com um simulador de realidade virtual para treinamento militar especializado
}

The user experience with a virtual reality simulator for specialized military training

\author{
Victor Nassar, Cassiano Canheti, André Salomão, Jonathan Nishida \& Milton Vieira
}

simulador, realidade virtual, treinamento militar

Simuladores de realidade virtual visam incluir os usuários em determinados contextos de experiências, proporcionando a prática de situações para o desempenho de tarefas do mundo real. No ambiente militar, simuladores são utilizados para treinamento de estratégias e formas de combate, utilização de equipamentos e veículos, entre outras aplicações voltadas à realização de exercícios. Tais ocorrências, no entanto, são desenvolvidas em um ambiente limitado, com restrição de movimentos e interações balizadas por botões do dispositivo. Assim, há uma lacuna para explorar diferentes possibilidades para adicionar mais camadas sensoriais aos simuladores, tornando os exercícios mais realistas e aumentando a precisão nos treinamentos, como a inclusão de objetos físicos ao ambiente, alterações no campo visual do usuário em movimento e o deslocamento corporal. A partir dessa abordagem, este artigo tem o objetivo de discutir uma proposta de método de pesquisa para analisar a experiência dos usuários com um simulador de realidade virtual para treinamento militar que permita a adaptação de cenários, com a personalização dos ambientes, tanto digital, quanto físico. Apresenta-se o desenvolvimento das etapas de pesquisa e analisa-se como o simulador pode representar avanços para o ensino teórico e aplicação prática de processos, auxiliando no conhecimento e na produção de dados.

\section{simulator, virtual reality, military training}

Virtual reality simulators aim to include users in certain contexts of experiences, providing the practice of situations for the performance of real-world tasks. In the military environment, simulators are used to train strategies and forms of combat, use of equipment and vehicles, among other applications aimed at performing exercises. Such occurrences, however, are developed in a limited environment, with restricted movement and interactions marked by device buttons. Thus, there is a gap to explore different possibilities for adding more sensory layers to the simulators, making the exercises more realistic and increasing the precision in the training, such as the inclusion of physical objects in the environment, changes in the visual field of the user in movement and the corporal displacement. From this approach, this article aims to discuss a proposed research method to analyze the users experience with a virtual reality simulator for military training that allows the adaptation of scenarios, with the personalization of environments, both digital, and physicist. It presents the development of the research stages and analyzes how the simulator can represent advances in theoretical teaching and practical application of processes, aiding in the knowledge and production of data.

\section{Introdução}

As características de um sistema de realidade virtual permitem criar uma imersão ao usuário, possibilitando-o interagir com um mundo virtual programado. É possível desenvolver esse mundo para atingir diferentes objetivos, como para parecer um ambiente real ou também para a criação de um universo imaginário. Além da habilidade de colocar o usuário em um mundo específico, outro elemento chave é a forma de interatividade que se existe na relação entre o universo e o usuário. Essa interatividade é feita por meio dos sensores de percepção do usuário, focado principalmente na visão, tátil, audição e movimento corporal. Com as estimulações sensoriais, é possível fazer o usuário se sentir como se estivesse presente dentro do universo da realidade virtual (Lavalle, 2017).

A partir desta natureza de imersão que a realidade virtual proporciona, é que se possibilita a sua aplicação em diferentes áreas, como, por exemplo, em treinamentos e educação, e não

Anais do 9 CIDI e 9 CONGIC

Luciane Maria Fadel, Carla Spinillo, Anderson Horta, Cristina Portugal (orgs.)

Sociedade Brasileira de Design da Informação - SBDI

Belo Horizonte | Brasil | 2019

ISBN $978-85-212-1728-2$
Proceedings of the 9th CIDI and 9th CONGIC

Luciane Maria Fadel, Carla Spinillo, Anderson Horta, Cristina Portugal (orgs.)

Sociedade Brasileira de Design da Informação - SBDI Belo Horizonte | Brazil | 2019

ISBN 978-85-212-1728-2 
apenas restrita a jogos ou pequenos projetos experienciais. As vantagens de se utilizar a realidade virtual estão refletidas na possibilidade executar formas mais participativas de se interagir com o ambiente, instigar o uso de diferentes formas sensoriais para interação e aprendizagem que não são possíveis de forma tradicional, além de criar um ambiente seguro para atividades (Kapp, Blair \& Mesch, 2014).

No treinamento militar, os simuladores podem atuar em diversas frentes, como: realizando voos por locais desconhecidos, simular uma situação de refém, no ensino de uso de tanques e veículos armados, para treinar soldados em ocasiões de situações críticas, entre outros. Essas e outras situações fazem parte do preparo militar e que exigem alta capacidade de sessões de treinamento. Assim, simuladores concedem formas de vivência, auxiliam na aquisição de experiência de atividades e práticas de tomada de decisão, tempo de reação, foco, atenção, domínio motor no manuseio do equipamento, entre outros.

Com isso, a utilização de um simulador de realidade virtual proporciona benefícios para o ensino teórico e aplicação prática de processos, auxiliando no conhecimento e na produção de dados, permitindo o aperfeiçoamento profissional e o ensino em ambiente controlado. Ressaltase o momento atual de reflexão e adequação de metodologias de ensino diante da aplicação de recursos hipermidiáticos tecnológicos de informação e comunicação. Entre os benefícios de se utilizar um simulador para realizar sessões de treinamento militar, destacam-se a redução de custo com munição e com viagens para locais específicos, o auxílio na avaliação de desempenho das tarefas realizadas, o registro digital com a sessão realizada, a criação de um histórico de cada indivíduo em cada tipo de atividade, a repetição de práticas de determinadas situações sem o desperdício de materiais, além de se evitar a degradação de equipamentos.

Contudo, em modelos de simuladores de treinamento tradicionais, o usuário permanece em um ambiente limitado, com movimentação restrita, reagindo e atuando com comandos de botões do dispositivo. Desse modo, há um campo de exploração que permite adicionar camadas sensoriais aos simuladores. Atuando com o deslocamento corporal, objetos físicos e alterações no campo visual do usuário, é viável aumentar a precisão nos treinamentos. Em movimento e com aparatos físicos no ambiente de treinamento, os exercícios podem tornar-se mais realistas, com métricas precisas de distância de objetos, peso e velocidade. Rever o posicionamento espacial, visual e sonoro, ampliam a percepção envolvida e permitem avaliação.

Neste cenário, os objetivos deste artigo estão voltados à discussão de uma proposta de método de pesquisa para analisar a experiência dos usuários com um simulador de realidade virtual para treinamento militar que permita a adaptação de cenários, com a personalização dos ambientes, tanto digital, quanto físico. Considerou-se a definição dos elementos que irão compor o software, os fluxos de informações e bases de dados, as necessidades para 0 controle, os meios humanos, técnicos e tecnológicos. De modo geral, tem-se o desenvolvimento das etapas de pesquisa e analisa-se como o simulador pode representar avanços para o ensino teórico e aplicação prática de processos, auxiliando no conhecimento e na produção de dados.

\section{Fundamentação teórica}

Dentro das áreas de aplicação da realidade virtual, está a criação de ambientes para treinamentos, focados no desenvolvimento de habilidades em determinadas tarefas do usuário. Ou seja, pode-se ter um simulador de treinamento de diferentes atividades, inclusive em situações consideradas de alto risco para o mundo real, uma vez que o indivíduo pode estar imerso no mundo virtual, recebendo estímulos sensoriais e praticando dentro de parâmetros predeterminados para não ocorrer acidentes físicos. Isso é possível porque a barreira que existe entre o usuário e o mundo virtual é quase não existente dentro da realidade virtual e consegue simular a experiência do mundo real dentro do virtual (Sherman \& Craig, 2003).

Assim, o objetivo de um simulador de realidade virtual é colocar o usuário em uma situação na qual deve executar determinadas tarefas para resolver as atividades propostas pela simulação. Por isso, simuladores devem conter as características necessárias para poder criar um modelo adequado de situações complexas do mundo real que o usuário irá interagir. O 
usuário precisa ter consciência do papel que ele está cumprindo dentro da simulação para que ele tenha noção das suas responsabilidades e limitações. O mundo virtual simulado precisa ser rico em informações com o objetivo de permitir ao usuário tomada de decisões. Por último, é necessário que o simulador contenha um sistema de feedback, para mostrar ao jogador seus erros e acertos (Gredler, 2004).

No contexto do ambiente militar, tem-se a aplicação de simulações para treinamento de estratégias e formas de combate que datam do Império Romano, bem como modalidades de jogos de batalha praticadas na Ásia, Oriente Médio e Europa (Smith, 2010). Atualmente, simuladores tecnológicos exploram variadas opções, com a criação de algoritmos e sistemas lógicos mais complexos (Christou, 2010) que possibilitam a utilização no ramo militar para diferentes propósitos, como para o treinamento de tropas em determinadas circunstâncias, para simular um treinamento de uma situação de refém, para o ensino de uso de tanques e veículos armados, para treinar soldados em ocasiões de ambientes críticos de sobrevivência, entre outros.

Ferreira e Silveira (2017) exemplificam a atuação de simuladores militares indicando as aplicações no ensino, para aprimoramento de capacidades como: a) comando, controle e consciência situacional; b) técnicas de progressão e formações de combate; c) técnicas de ocupação de posição de tiro com blindados; d) preparação, planejamento e execução do apoio de fogo nível subunidade; e) exploração rádio; f) técnicas de ação durante o contato; g) técnicas de ação imediata; h) utilização e ocupação do terreno para observação e tiro; i) identificação de blindados; j) técnicas de prevenção de fratricídio; k) trabalhos de apoio ao movimento (transposição de obstáculos e aberturas de brecha); I) ordens fragmentárias; m) operações ofensivas; n) operações defensivas; e o) reconhecimento e segurança; entre tantos outros.

Entre os benefícios de se utilizar um simulador para realizar sessões de treinamento militar, destacam-se a redução de custo com munição e com viagens para locais específicos, o auxílio na avaliação de desempenho das tarefas realizadas, o registro digital com a sessão realizada, a criação de um histórico de cada indivíduo em cada tipo de atividade, a repetição de práticas de determinadas situações sem o desperdício de materiais, além de se evitar a degradação de equipamentos.

De acordo com Ferreira e Silveira (2017), a simulação virtual tática permite ainda vantagens, como: a) Fornece um ambiente seguro, controlado e de baixo custo no qual o aprimoramento das capacidades de combate podem ser otimizados no ambiente ao vivo; b) Possibilita a integração das diversas funções de combate e a utilização de uma infinidade de meios que, em uma situação real, seriam difíceis de reunir e gerariam elevado custo; c) Pode ser acompanhada facilmente por uma equipe de especialistas que controlam e avaliam as atividades, reproduzindo os resultados positivos e negativos posteriormente aos instruídos através das ferramentas de análise pós-ação; d) Diminui a necessidade de utilização de campos de instrução preservando áreas e colaborando com a preservação do meio ambiente; e) minimiza a necessidade de controle e gestão de danos a estruturas existentes, como estradas e cercas; f) Consegue simular de maneira limitada, porém satisfatória, a execução de atividades de alto risco como abertura de brechas, transposição de cursos d'água, além dos efeitos dos fogos inimigos sobre a tropa e sua consequente degradação.

\section{Projeto Simulador de Treinamento Militar}

Neste cenário, os objetivos do projeto estão voltados à pesquisa e desenvolvimento de simulador de realidade virtual imersiva para treinamento militar que permite a adaptação de cenário de ambiente digital de acordo com o ambiente físico.

O projeto do simulador pretende realizar treinamento dentro das seguintes atividades:

- Combate urbano com uso de armas de fogo; Escalada em ambientes externos; Descida em rapel de helicópteros; Salto de paraquedas; Navegação em locais de frio e calor extremos.

A proposta divide o escopo em quatro aspectos diferentes: 
- Treinamento de combate: uso de equipamento de realidade virtual e software com capacidade de simular os aspectos de uma ação de combate com armas de fogo.

- Treinamento de ações em situações de risco: uso de equipamento de realidade virtual em conjunto com outras tecnologias para simular as atividades de escalada, rapel, paraquedismo e navegação em regiões extremas como geleiras e desertos.

- Editor de cenários: um software que oferece o usuário a capacidade de criar os cenários a serem utilizados no treinamento de combate. O usuário poderá construir cenários com medidas de distância e disposição de elementos reais, sem a necessidade de conhecimento especializado em programação.

- Manual de recursos físicos: um manual com as informações necessárias de como construir, instalar e configurar os artefatos físicos adequados para a realização de cada treinamento possível, incluindo as definições técnicas para cada situação e informações sobre as especificações de cada artefato.

\section{Etapas de desenvolvimento}

\section{Etapa 1 - Estabelecimento de modelo de classificação de simulação física por meio de equipamentos de realidade virtual imersiva}

- Identificação de simuladores de realidade virtual imersiva.

- Análise de características e funcionamento da simulação física por meio de equipamento de realidade virtual imersiva.

- Definição de parâmetros de classificação.

\section{Etapa 2 - Análise da experiência do usuário em simuladores de realidade virtual para treinamento militar}

- Identificação de simuladores de realidade virtual voltados para práticas de treinamento militar (combate e situações de risco).

- Definição de parâmetros de avaliação de desempenho do usuário em treinamento militar (combate e situações de risco).

- Estruturação de modelo comparativo de treinamento físico $x$ treinamento em simulador de realidade virtual.

Etapa 3 - Modelo de editor de cenários em simulador de realidade virtual imersiva para a adaptação de ambiente digital de acordo com o ambiente físico

- Análise de simuladores de realidade virtual que permitem a edição de cenários de ambiente virtual para a adaptação com ambiente físico.

- Estabelecimento de requisitos para a adaptação de ambientes digital e físico.

- Estabelecimento de requisitos para a montagem do layout e para a construção de objetos do ambiente físico na adaptação ao ambiente digital de um simulador personalizável.

Etapa 4 - Desenvolvimento de simulador de realidade virtual imersiva de treinamento militar que permite a adaptação de ambiente digital de acordo com o ambiente físico

- Identificação de práticas de treinamento militar com possibilidades de inclusão no 
Nassar, V., Canheti, C., Salomão, A., Nishida, J., \& Vieira, M.

A experiência do usuário com um simulador de realidade virtual para treinamento militar especializado

simulador de realidade virtual imersiva que permite a adaptação de ambientes digital e físico.

- Definição de critérios de adaptação do treinamento militar para a adequação ao treinamento em simulador de realidade virtual imersiva com ambientes físicos e digitais personalizáveis.

- Estabelecimento de requisitos de projeto de simulador de realidade virtual imersiva de treinamento militar que permite adaptação de ambientes digital e físico.

- Desenvolvimento de software de simulador de realidade virtual imersiva para treinamento militar que permite a adaptação de ambientes digital e físico.

- Análise da experiência de usuários com o simulador de realidade virtual imersiva desenvolvido.

\section{Considerações}

De modo geral, este artigo apresentou uma proposta de pesquisa que enfatiza a relação da experiência do usuário com aplicações tecnológicas na área da defesa nacional, em específico para treinamento militar, analisando como um simulador de realidade virtual imersiva pode representar avanços para o ensino teórico e aplicação prática de processos, auxiliando no conhecimento e na produção de dados. Para tanto, serão pesquisados, experimentados e desenvolvidos métodos, ferramentas, análises dos fatores humanos e ergonômicos (Reid Compton, Grossman, \& Fanjiang 2005), que são áreas de conhecimento das ciências sociais aplicadas e de atuações do design para analisar e projetar serviços e produtos. Ressalta-se que a tecnologia e o design de interação estão inseridos na sociedade ao participarem do modo de vida das pessoas, na maneira como consomem e produzem informações, em como se relacionam entre si e com o meio.

A proposta de um simulador de treinamento capaz de realizar a edição de cenários e respectiva adaptação de ambientes digitais e físicos permite explorar um aspecto de inovação tecnológica. Não importa o tipo ou função do simulador, os ambientes são embasados em métricas de performance reais, retiradas da ação prática que o simulador está baseado. É um aspecto relevante, pois muitas vezes não há uma relação direta entre o comportamento e as métricas. Normalmente, há fatores intermediários que impactam nas métricas, o que acaba por dificultar o entendimento de como determinados comportamentos impactaram no resultado. Esse é o motivo da necessidade de um manual com as posturas de logística e ergonomia adequados do maior número possível de variáveis que estarão sendo trabalhadas no simulador, como medidas de distância, peso, velocidade e direção do vento, temperatura e outras a serem definidas no decorrer da pesquisa.

Com o desenvolvimento de um simulador de realidade virtual imersiva, podem-se obter avanços para o ensino teórico e aplicação prática de processos, auxiliando no conhecimento e na produção de dados, permitindo o aperfeiçoamento profissional e o ensino em ambiente controlado. Ressalta-se o momento atual de reflexão e adequação de metodologias de ensino diante da aplicação de recursos hipermidiáticos tecnológicos de informação e comunicação.

Há de se ressaltar também a carência na produção científica de materiais específicos voltados às áreas de segurança territorial, treinamento militar e defesa nacional como um todo. Desse modo, o projeto configura-se como elemento relevante para pesquisas com foco multidisciplinares, que busquem abranger demandas da sociedade em termos de projetos militares. Com o foco da pesquisa em mídia, tecnologia e inovação, possibilita-se impacto significativo nas produções acadêmicas referentes a simuladores de realidade virtual, produção de games, design de interação, entre outras áreas de conhecimento correlatas. Além disso, o projeto pode oferecer em relação à análise e discussão de métodos de pesquisa e desenvolvimento de experimentos com simuladores de realidade virtual para treinamento militar. 


\section{Agradecimento}

Agradecemos o apoio e financiamento de Capes, CNPq e Universidade Federal de Santa Catarina,bem como à equipe do DesignLab/UFSC pela colaboração com as pesquisas.

\section{Referências}

Ferreira, V. E. N., \& Silveira, A. L. C. A Simulação Virtual Tática No Ensino E No Treinamento Militar. Escotilha do Comandante, (2017). Disponível em:

$<$ <ttp://www.cibld.eb.mil.br/index.php/periodicos/escotilha-do-comandante/338-asimulação-virtual-tática-no-ensino-e-no-treinamento-militar. Acesso em: 10 ago, 2018.

Gredler, M. (2004). Games and simulations and their relationships to learning. Handbook of Research on Educational Communications and Technology.

Kapp, K. M., Blair, L., \& Mesch, R. (2014). The Gamification of Learning and Instruction Fieldbook - ideas into Practice. Wiley: San Francisco, CA.

Lavalle, S. M. (2017). Virtual Reality, Cambridge University Press.

Reid, P. R., Compton, W. D., Grossman, J. H., \& Fanjiang, G. Building a Better Delivery System. (2005). A New Engineering/Health Care Partnership. The National Academies Press, Washington, D.C..

Sherman, W. R., \& Craig, A. B. (2003). Understanding Virtual Reality: Interface, Application, and Design. Elsevier Science (USA).

Smith, R. (2010). The Long History of Gaming in Military Training. Simulation \& Gaming Simulat Gaming. 41. 6-19. DOI: 10.1177/1046878109334330.

\section{Sobre o(a/s) autor(a/es)}

Victor Nassar, Dr., UFSC, Brasil <victornassar@gmail.com>

Cassiano Canheti, Mestrando, UFSC, Brasil <canheti@gmail.com>

André Salomão, Mestrando, UFSC, Brasil <andresalomao3d@gmail.com>

Jonathan Nishida, M. Sc., UFSC, Brasil <jounishida@gmail.com>

Milton Vieira, Dr., UFSC, Brasil <milton.vieira@ufsc.br> 